\title{
The Relationship between Parenting Styles and Behavioral Problems among Bahraini Preschoolers
}

\author{
Amina Al- Hajeri, ${ }^{1}$ \\ University of Bahrain, Kingdom of Bahrain
}

Received: $11^{\text {th }}$ Oct 2020 Revised: $16^{\text {th }}$ Oct 2020 Accepted: $18^{\text {th }}$ Oct $2020 \quad$ DOI: https://doi.org/ $10.31559 /$ CCSE2020.1.1.4

Abstract: The aim of the present study was to explore the relationship between Bahrainis' mothers parenting styles and their young children behavioral problems. The sample composed of 255 mothers and 255 teachers of preschool children. Mothers responded to the Parenting Style Instrument whereas the teachers of the same children responded to the Behavioral Problems Instrument. The results indicated that authoritarian parenting style $(42.69 \%)$ was the dominant style among Bahraini mothers of preschoolers from mothers' perceptions. It is followed by cruelty style (13.04\%) and authoritative style (11.86\%). The results also showed a significant correlation between two parenting styles authoritarian and cruelty used by Bahraini mothers and attention deficit, hyperactivity and impulsiveness, and aggression among Bahraini preschoolers. It was found the authoritarian style is positively correlated with the three behavioral problems; whereas the cruelty style is positively correlated with aggression only.

Keywords: Parenting styles; Behavioral problems; Authoritarian- Authoritative; Attention deficit; Hyperactivity and impulsiveness-Aggression.

1 Corresponding author

Amina Al- Hajeri

Assistant Professor, University of Bahrain, Bahrain.

E-mail: harmas2@yahoo.com 
International Journal of Childhood, Counselling, \& Special Education (CCSE), Volume1, Issue: 1 , September: 2020, pp.58-78

\section{Introduction}

Early childhood is the most important developmental period of human life. During this period his personality will develop and he will learn different pattern of thinking, behavior and construct basic cognitive concepts and knowledge. Fraud (in Abdul rahman, 1998) indicated that the child's experiences during the first five years of his life has a great influence on the development of his personality and the future crisis or the maladjustment problems he comes across are the results of maltreatment during this critical period. Janus (2010) reported presence of evidence that behavior problems considered as one of the crucial factors which put children at risk for school failure. Children learn behavior through their interaction with environment. At home they interact with parents, relative and others in the neighborhood whereas at preschool they interact with teachers and peers. They are also influenced by media including new technology.

In the United States, Anderson (1983) found that aggression (44\%), anxiety (39\%) and attention deficit and hyperactivity $(17 \%)$ were the most prevalent behavioral problems among disadvantages preschool children from their teacher perspective.

In Riyadh the capital of Saudi Arabia, Al-Laheeb (1986) reported that stubbornness, temper tantrums, insisting to sleep with the mother, grasp attention and fear of darkness were the prevalent problems among preschool children from the perspective of both teachers and mothers.

In Ontario, Achenbach, Howell, Quay and Conners (1991) reported three prevalent behavioral problems among Canadian preschool children: Attention deficit (22\%), anxiety and aggression (15\%) from both parent's perspectives.

In Bahrain, Alomran and Ubada (1993) explored preschool children problems from both parents' perspectives. They developed a checklist of 25 problems which included some emotional and behavioral problems. The results revealed four prevalent problems. These were Jealousy (76.31\%), nutrition $(73.69 \%)$, fear $(72.38 \%)$ and hyperactivity (70.63\%).

At Mekka city in Saudi Arabia, Alharbi (2001) conducted a comparative study on behavioral problems from mother perspective between preschool children in urban and rural areas. It was found that hyperactivity is the most prevalent problem and it was spread among children in urban areas $(68.87 \%)$ more than their counterparts in rural areas (64.50\%). The second problem was temper 
International Journal of Childhood, Counselling, \& Special Education (CCSE), Volume1, Issue: 1 , September: 2020, pp.58-78

tantrum and it was also located among urban preschool children $(46.25 \%)$ more than the children in the rural areas $(44.75 \%)$.

In Oman, Alsharbati, Alhussaini \& Antony (2003) found hyperactivity (60\%), aggression $(49 \%)$ and stealing (52\%) as prevalent behavioral problems among Omani preschool children.

In Egypt, Fared, Abou-Hatab \& Okasha (2005) found that the most prevalent behavioral problems preschool children from the teacher's perspective (using Connor's rating scale) were attention deficit (6.1\%), adaption (5.6\%) and hyperactivity (4.1\%).

In Germany, Furniss, Beyer \& Guggenmos (2006) reported that the highest prevalent behavioral problem among preschool children from the mother perspective was anxiety. Then come was withdrawn, and attention deficit respectively.

In Kuwait, Alsahel's study (2006) revealed that aggression (44.9. $59.2 \%)$, hyperactivity (30.6-41.9\%) and stubbornness (27.6-37.7\%) were the most prevalent behavioral problems among preschool children from teacher perspective.

In Iran, Hebrani, Abdolahian, Behdani, Vosoogh \& Javanbakht (2007) reported that Attention deficit and hyperactivity (ADHD) is the most prevalent behavioral problem $(12.3 \%)$ from both teachers and parents' perspective using Connor's rating scale.

In Brazil, Anelmi, et al (2008) found that aggression (0.39) and attention deficit (0.37) were the prevalent behavioral problems among the preschool children from mothers' perspective.

In Canada another study was carried out by Janus (2010) to investigate the prevalent behavioral problems among preschool children from parent's perspective. She used different instrument from Achenbach, Howell, Quay and Conners (1991). It was found that temper tantrum (3.9-10.5\%), aggression $\quad(2.1-8.9 \%) \quad$ and hyperactivity $(3.5-8.2 \%)$ were the main problems in respective order. Aggression is the common problem in the two studies.

In the United States, another study (Espy, Sheffield, Wiebe, Clark, $\&$ Moehr, 2011) was conducted to explore the prevalent behavioral problems among general preschool population in Nabraska using different instruments. The results showed that Hyperactivity was the highest prevalent problem and the second was attention deficit.

In Libya, Zeglam \& Darrat (2011) reported that aggression was the most prevalent behavioral problem (44\%) from mother perspective. 
International Journal of Childhood, Counselling, \& Special Education (CCSE), Volume1, Issue: 1 , September: 2020, pp.58-78

In Thailand, Wu, et. al (2012) found that withdrawn (13.5\%) and Sleeping disorder $(8.5 \%)$ were the most prevalent behavioral problems among young children from their mother's perspective.

In Bahrain, another study was conducted by Al Hajeri (2014) to identify the prevalence behavioral problems only among Bahraini preschool children from the teacher perspective. The researcher developed her own instrument which included 8 problems (aggression, hyperactivity, stubbornness, attention deficit, lying, fear, jealousy and stealing). Using factor analysis, the results revealed three prevalence behavioral problems and these were attention deficits (24.34\%), hyperactivity and impulsiveness (22.10\%) and aggression (21.88\%) respectively.

Baumrind (1971) described three models or constructs of parenting styles: permissive, authoritarian, and authoritative. Maccoby and Martin (1983) added a fourth style which is neglectful or uninvolved. Baumarid (1991) described two dimensions for parenting practice. These are control and responsiveness (Affection). Control defines (Baumrind, 1991: 61-62) as "the claims parents make on children to become integrated into the family whole, by their maturity demands, supervision, disciplinary efforts and willingness to confront the child who disobeys". Parental responsiveness (Baumrind, 1991: 62) defined as 'the extent to which parents intentionally foster individuality, self-regulation, and self-assertion by being attuned, supportive, and acquiescent to children's needs and demands. These styles composed of a combination of responsiveness and control but with different amount (Gracia \& Gracia, 2009). They vary based on the extent of the parental authority or control on their children activities and the affection provided.

For instance, a balanced of both is expected in authoritative style. Parents who use this style support their children and provide children with their needs. They determine rules and expectations for them. They select indirect methods in rearing which encourage the children to be independent and participate in open communication. Authoritative parents provide children with their needs (responsive) and they set up rules (Baumrind, 1971). They help them to develop autonomy, active thinking which might lead to social and academic competence (Walker, 2010). They are aware of both parents and child rights (Darling \& Steinberg, 1993).

Research (Baumrind 1991; Dekovic \& Janssens, 1992; Denham 
International Journal of Childhood, Counselling, \& Special Education (CCSE), Volume1, Issue: 1 , September: 2020, pp.58-78

et al, 2000; Kochanska, 1991; Lamborn, Mants, Steinberg, \& Dornbusch, 1991; Pearson \& Rao, 2003) revealed that the preschool children of authoritative parents were more socially competent and have positive relationships with peers compared to children of parents who use other styles. They work on a task with confident and they could regulate their emotions very well.

Lin and $\mathrm{Fu}$ (1990) and Chao (1994) indicated that Baumrind model were mainly used in European and American culture. Querido, Warner, and Eyberg (2002) indicated that Cross cultural differences such as cultural beliefs, concepts, preference and standard of competence have influences on parenting styles. For instance, in a comparison study (O'Reilly, Tokuno \& Ebata, 1986) between Japanese American and European American parenting styles, it was found that the first group appreciated well behaving whereas the second positively perceived self-directed and tolerance behavior.

Another study (Kinght, Virdin \& Roosa, 1994) indicated that Hispanic parents preferred authoritarian and punitive styles compared with European American parents. This finding was disputed by the study of Calzada and Eyberg (2010) with Dominican and Puerto Rican immigrant mothers of preschoolers who found that the mothers used high level of authoritative parenting style and lower levels of both authoritarian and permissive styles. However, there was a difference between them on the authoritative parenting style for the benefit of the Dominican mothers. It is indicated that a higher authoritative style was correlated with high paternal education and younger age of the child. Chao and Sue (cited in Dwairy et al, 2006) argued about Baumrind and said that parenting means interaction with children, dedication and make sacrifices for the benefit of the child . Family based control is perceived as supportive by parents and children. Kagitcibasi (2005) who studies parenting in Turkey also mentioned that parental control and warmth should be perceived as compatible with each other rather than competitive. Alizadeh and Andries (2002) found Iranian parents of children with attention deficit hyperactivity disorder (ADHD) used more authoritarian style and less authoritative style than parents of children with no (ADHD).

In Arabic culture, Dwairy et al (2006) found three parenting patterns; inconsistent, controlling and authoritarian were used by parents of adolescents in eight Arab societies. They form of a different proportion combination of two of three styles authoritative, permissive and authoritarian. It was indicated that parenting patterns are 
International Journal of Childhood, Counselling, \& Special Education (CCSE), Volume1, Issue: 1, September: 2020, pp.58-78

associated with the social political system in the countries.

Mehriz (2005) found a significant correlation between authoritative and permissive parenting styles and Syrian preschool children social and personal interaction in the preschool. She also found a negative significant correlation between authoritarian, punishment, neglect, discriminatory parenting styles and children social and personal interaction in the preschool. Dwairy (2008) found that parental inconsistency is associated with psychopathology. Algusoon (1993) found a relationship between aggressive behavior in Saudi preschool children and authoritarian, discriminatory, and permissive parenting styles. Research (Hurd, Moore, \& Roger, 1995) indicated that African American enhanced share responsibilities between parents and they use physical punishment more often that European American. Baumrind (1991) did not found a relationship on African American study between authoritarian parenting and behavioral problems in children. A support argument was found in Deater-Deckerd, Dodge, Bates and Pettit (1986) study. They revealed positive correlation between physical discipline use by mothers and child behavioral problems behavior.
Atrees (2010) conducted a study on Algerian families in order to identify negative parenting practice (authoritarian, overprotective and permissive, cruelty and neglect) and their association to some preschool behavioral problems (anger, stubbornness and aggression). It was found that no sex discrimination in negative parental practice. The preference of the style was authoritarian. Atrees explained that parents might view these practice as correct. He also found a significant association between authoritarian style, anger and aggression only. Overprotective and permissive style was associated with anger whereas cruelty was correlated with the three behavioral problems. He argued that parents use authoritarian style because they think that their child is still young and cannot identify what is best for him. He explained that parents use overprotective and permissive style is motivated by love to the child.

Abu Taleb (2012) explored four parental styles (authoritative, permissive, uninvolved and authoritarian) among Jordan mothers of 4 years old preschool children and its relationship with mothers' perceptions of their children's social skills. It was found that authoritative parenting $(73.5 \%)$ was the most prevalence style. Then, comes permissive (20\%), authoritarian (4.3\%) and uninvolved (2.3\%). He explained that Jordan is a 
International Journal of Childhood, Counselling, \& Special Education (CCSE), Volume1, Issue: 1 , September: 2020, pp.58-78

moderate society which is trying to practice democracy. He added that the mothers were involved in social program such as "better parenting" which was initiated in 1996 in order to provide children with their needs. A third interpretation might that the mothers want to expose themselves as authoritative to other, so they selected the items which describe this style. It was revealed that authoritative mothers perceived their children more positively in terms of their social skills compared to permissive, uninvolved and authoritarian mothers. Abu Taleb argued that the result reflects the Jordan culture which focus on enhancing group relationship from early years.

It could be observed from the previous studies that the prevalent behavioral problems in the world are hyperactivity, attention deficit and aggression respectively. Specifically, in the Arab world the main problems were hyperactivity and aggression whereas in the western society's aggression and attention deficit respectively. However, in Thailand the prevalent behavioral problems (withdrawn and sleeping disorders) were the traditional ones and completely different from other countries. The reason could be the calmness nature of the people and the culture in that part of the world. The researcher interpred the variation the percentage and order of the behavioral problems in the previous studies could be related to the different procedures used in the studies such as the type of the instruments, the selection of the samples and the numbers, and the source of the information. The research revealed the increase interest in exploring behavioral problems in the childhood period in the period 2000 and 2014 compared to the eighties and nineties.

The results of the GCC might reflect the tremendous fast changes that took place in this area in terms of modernasation and the unstabilities. Children as part of the societies are naturally influenced by such circumstances.

Early childhood is an important period in a child's life. In Bahrain, the field of childhood has insuffient number of expertise and body of research in this area. One possible reason is that early childhood education is under private sector. As a consequence, there is scarcity in the information on children learning, development, class environment, teacher's training and parenting styles. There is a need for a vast of research in these different areas of childhood. This study is an extending of a previous study (Al Hajeri, 2014) which was on identifying the prevalence behavioral problems among Bahraini preschool children from the teacher perspective. The study revealed three prevalence behavioral problems and 
International Journal of Childhood, Counselling, \& Special Education (CCSE), Volume1, Issue: 1 , September: 2020, pp.58-78

these were attention deficits, hyperactivity and impulsiveness and aggression respectively. The researcher believes that parents play a vital role in their children lives. They have a great influence in shaping their children's behaviors in dealing with others, developing their self-esteem (Webster-Stratton, 1988). Parents' personality and perceptions (Glascoe \& Leew, 2010) of their children have an effect on young children, behavior. The main aim of the present study was to explore the relationship between Bahraini mother parenting styles and the behavioral problems among Bahraini preschoolers.

Based on the previous literature which was collected shows scarcity in the studies of parenting styles used with preschool children in Arabic societies in general and in Bahrain in specific. The present study purpose was to explore the prevalence parenting style used in a sample of Bahrainis mothers with their preschool children age 4-6 years old. It also investigated the relationship between the parenting styles and the 3 prevalence behavioral problems among preschool children in the Kingdom of Bahrain.

Previous reviews have identified the preschool years as a critical point for intervention. Children interact with preschool and home context during his daily life. There is a need to study his behavioral from both teachers and parents' perspectives. Research indicated the importance of evaluating the management strategies used by parents and teachers to deal with the behavioral problems of preschool children (Kazdin \& Weisz, 1998; Morrison, Macdonald, \& LeBlanc, 1999; Reginald \& Nixon, 2002 in Herrera and Little, 2005).

Based on the previous literature which was collected shows scarcity in the studies of parenting styles used with preschool children in Arabic societies in general and in Bahrain in specific. As being

The present study purpose was to explore the prevalence parenting style used in a sample of Bahrainis mothers with their preschool children age 4-6 years old. It also investigated the relationship between the parenting styles and the 3 prevalence behavioral problems among preschool children in the Kingdom of Bahrain.

\section{Method}

\section{Sample}

The participants in this research were 255 preschool teachers and mothers of children aged 4-6 who attended private preschool in the kingdom of Bahrain. The researcher distributed two instruments through the preschools. The original number of the distributed instruments was 400 , but the returned was 255 only. 
International Journal of Childhood, Counselling, \& Special Education (CCSE), Volume1, Issue: 1 , September: 2020, pp.58-78

Most of the missing forms were the mothers' forms.

\section{Measures and procedures}

Two instruments were used in this study. These are:

A validated behavioral problem instrument called "Sahha" which was developed by the researcher in a previous study (Al Hajer, 2013). The instrument consists of 32 items which represent 3 prevalent behavioral problems among preschool children aged 3-6 in Bahrain. These are attention deficits, hyperactivities and compulsiveness and aggression. Factor analysis a form of construct validity in order was conducted to find the validity of the instrument and $(r)$ was $=(0.31$ $0.82)$ for the statements in the three factors (behavioral problems). Cronbach alpha was used to calculate the reliability of the instrument. The values for the three subscales were:

Table 1 . The validity and the reliability of the three subscales in the behavioral problems instrument

\begin{tabular}{lllll}
\hline Operation & Type & $\begin{array}{l}\text { Subscale 1 (Attention } \\
\text { deficits Problem) }\end{array}$ & $\begin{array}{l}\text { Subscale2 } \\
\text { (Hyperactivity } \\
\text { Compulsiveness) }\end{array}$ & $\begin{array}{l}\text { Subscale3 } \\
\text { \& Aggression) }\end{array}$ \\
\hline $\begin{array}{l}\text { Construct } \\
\text { validity }\end{array}$ & $\begin{array}{l}\text { Item total correlation as } \\
\text { a measure of internal } \\
\text { consistency } \\
\text { analysis) }\end{array}$ & $0.36-0.75$ & $0.34-0.82$ & $0.31-0.65$ \\
(Factor & & & \\
Reliability & \begin{tabular}{l} 
Cronbach Alpha \\
\hline
\end{tabular}
\end{tabular}

2. Parenting Style Instrument (PSI) was developed by the researcher for the purpose of this study.

\section{Development of the Parenting Style Instrument (PSI)}

Parenting Style Instrument is developed in order to identify the most popular parenting styles used by Bahraini mothers with their preschool children. The researcher reviewed some previous studies in this area (Parenting Styles and Dimensions PSD; Robinson, Hart, Mandleco, \& Frost Olsen, 1996; Parenting style questionnaire;
Mihriz, 2002; Mothers' parenting style questionnaire; Abu Taleb, 2012) and developed the first form of the instrument. This form was composed of 74 items which describe the behavior of mothers with their children. They were distributed through 7 subscales (Dimensions)as follows:

1. Democratic style (14)

2. Authoritarian style (17)

3. Over protective and permissive (9)

4. Acceptance style (6) 
International Journal of Childhood, Counselling, \& Special Education (CCSE), Volume1, Issue: 1 , September: 2020, pp.58-78

5. Discriminative style (13)

6. Punishment style (10)

7. Neglect style (5)

A five-point Likert scale was used to each item or statement:

Always $=5$, mostly $=4$, sometimes $=3$, $f_{e w}=2$, rarely $=1$.

The instrument was reviewed by three faculty members from Education and Psychology Departments in the University of Bahrain and Arabian Gulf University. Some modifications were made such as changing the negative statements into positive and shifting some items from one subscale to another. In this research the Democratic style is treated as Authoritative style.

Validation of Parenting Styles

\section{Instrument}

\section{Pilot study}

The first form of the Parenting Styles Instrument was administered to a pilot sample consisting of 32 preschool teachers and 32 mothers

Table 2. Values of Cronbach Alpha for the 7 subscales in the Parenting Styles Instrument

\begin{tabular}{llcccccc}
\hline Subscale & 1 & 2 & 3 & 4 & 5 & 6 & 7 \\
\hline Cronach Alpha & 0.714 & 0.715 & 0.642 & 0.663 & 0.741 & 0.638 & 0.600 \\
\hline
\end{tabular}

The values of Cronbach Alpha in Table (2) showed that Parenting Style Instrument is reliable. of 4-6 years old children. The sample was withdrawn from 3 preschools located in 2 different cities in The Kingdom of Bahrain. The teacher was asked to identify a child in her class who she suspected to have some symptoms of Attention Deficit, Hyperactivity and Impulsiveness, or Aggression. Then, she was asked to complete the behavioral problems instrument ("Sahha"). At the same time, a copy of the Parenting Styles Instrument was completed by the mother of the same child. The following is the reliability and the validity of the Parenting Styles Instrument for this pilot study.

\section{Reliability}

Cronbach alpha was used to determine the internal consistency of Parenting Style Instrument. The calculated value of $(\alpha)=0.820$ when 51 items out of 70 were considered. This value is high and it shows that the Parenting Style Instrument is reliable. The researcher also found Cronbach Alpha for each subscale in sequence as Table 2 .

\section{Construct Validity}

Correlation between the score of each item in each dimension and the 
International Journal of Childhood, Counselling, \& Special Education (CCSE), Volume1, Issue: 1 , September: 2020, pp.58-78

total score of the dimension was used

as an evidence of construct validity.

Table 3. Correlation between the score of each item and the total score of Democratic parenting style (subscale1)

\begin{tabular}{lll}
\hline No & Item & $(r)$ \\
\hline 1 & I discuss with my child things concerned him before taking decision. & $0.407^{*}$ \\
2 & I considered my child wish in family plan (weekend plan). & $0.625^{* *}$ \\
14 & I take my child for shopping to select his own clothes and toys. & $0.468^{* *}$ \\
18 & I tell my child my point of view in the problems that he comes across & $0.635^{* *}$ \\
24 & I encourage my child to solve his own problems (such as problems with peers). & 0.217 \\
35 & I let my child to participate in setting rules at home. & 0.249 \\
48 & I respect my child his opinion even if it is different than mine & $0.519^{* *}$ \\
51 & I spend sometimes alone with my child (talk or doing an activity) & 0.134 \\
54 & I treat my child as a respected member in the family & 0.090 \\
60 & I understand his emotion when he is upsets or distress & 0.249 \\
63 & I talk or express myself when my child misbehaves & $0.460^{* *}$ \\
74 & I praise my child when he does something good & 0.147 \\
1 & I discuss with my child things concerned him before taking decision. & $0.407^{*}$ \\
\hline
\end{tabular}

The results in Table (3) showed that the score of 6 items have significant correlation with the total score of democratic) subscale only.
All of them are at 0.01 level of significant except item no. 1 at 0.05 level. Item no. 18 has the highest significant.

Table 4. Correlation between the score of single item and the total score of Authoritarian parenting style (dimension2)

\begin{tabular}{lll}
\hline No & Statement & $(\mathrm{r})$ \\
\hline 3 & I explode in anger in my child face & $0.396^{*}$ \\
16 & I lay rules for my child and I determine the consequence of violating them & -0.011 \\
17 & I stop my child from doing activities that require physical motion & $0.574^{* *}$ \\
19 & I punish my child by with draw some privilege (watch T.V) & 0.279 \\
27 & I yell at my child when he bothers me or does what I disapprove & $0.592^{* *}$ \\
29 & If my child attempted to talk I stop him vigorously & $0.564^{* *}$ \\
30 & I use harsh words which hurt when he misbehaves & $0.669^{* *}$ \\
40 & I force him/her to eat certain food and cloths & $0.398^{*}$ \\
44 & I do not allow him \her to discuss my instructions & $0.638^{* *}$ \\
59 & I used terms such as this is wrong or forbidden a lot & 0.311 \\
62 & I set up sleeping time for my child through the week & 0.005 \\
72 & I take my decisions on issues related to my child & 0.304 \\
\hline
\end{tabular}

The results in Table (4) showed 7 significant correlations only. All of them at 0.01 level of significant except item no. 2 at 0.05 level. Item no. 30 has the highest correlation.
All of the 7 items were included when reliability was carried out using cronbach alpha. The researcher decided to keep these items only in the parenting list. 
International Journal of Childhood, Counselling, \& Special Education (CCSE), Volume1, Issue: 1 , September: 2020, pp.58-78

Table 5. Correlation between the score of single item and the total score of permissive and Overprotective parenting style (dimension3)

\begin{tabular}{|c|c|c|}
\hline $\mathrm{No}$ & Item & $(\mathrm{r})$ \\
\hline 5 & I threat my child of punishment, but I change my mind after a while. & $0.588^{* *}$ \\
\hline 6 & I stop punishment for my child before the preset time & $0.723^{* *}$ \\
\hline 8 & The punishment my child receives depends on my mood at that time. & $0.526^{* *}$ \\
\hline 13 & I do not allow my child from interaction with other child. & 0.329 \\
\hline 36 & $\begin{array}{l}\text { I asked my child's teacher not to allow him } \backslash \text { her to play in sand or clay to } \\
\text { avoid getting dirty. }\end{array}$ & 0.172 \\
\hline 52 & $\begin{array}{l}\text { I do some of my child's homework to prevent him from receiving } \\
\text { punishment }\end{array}$ & 0.257 \\
\hline 53 & I worried about my child's health & 0.03 \\
\hline 56 & I am permissive when he $\backslash$ she make a mass & $0.325^{*}$ \\
\hline 57 & I do not allow him $\backslash$ her to participate in the school trips for fear it & $0.603^{* *}$ \\
\hline 71 & I do not place certain rules for my child & $0.423^{*}$ \\
\hline 76 & I contact my child's school frequently asking about him or her. & 0.162 \\
\hline
\end{tabular}

The results in Table (5) showed 6 at the level of 0.01 and the rest were significant correlations only. 4 were at 0.05 level. The highest correlation was in item no. 6 .

Table 6. Correlation between the score of single item and the total score of Acceptance parenting style (dimension4)

\begin{tabular}{lll}
\hline No & Items & $(\mathrm{r})$ \\
\hline 4 & I praise his $\backslash$ her performance or behavior in front of others & 0.199 \\
26 & I express myself verbally to my child that I am happy for helping me at home & 0.094 \\
33 & I give my child gifts of his preference at occasions (birthday) & $0.723^{* *}$ \\
38 & I allow my child to participate in the activities as long as they are not harmful & 0.304 \\
39 & I reward my child when he follows my instructions or behave well & 0.217 \\
43 & I tell my child that he did a good job & 0.019 \\
45 & I hug and kiss my child telling him that I do that because he is my child. & $0.475^{* *}$ \\
49 & I ignore some of my child behaviors & 0.240 \\
55 & I accompany my child with me when I visit my relatives and friends and & 0.296 \\
& show him how please I am & \\
64 & I tell my child I was so happy when I gave birth to him \her and I still do so & 0.145 \\
\hline
\end{tabular}

The results in Table (6) showed 2 The researcher decided to keep these significant correlations only. Both of two items. them were at the level of 0.01 . Item no. 33 had the highest correlation. 
International Journal of Childhood, Counselling, \& Special Education (CCSE), Volume1, Issue: 1 , September: 2020, pp.58-78

Table 7. Correlation between the score of single item and the total score of Discriminatory style parenting style (dimension 5)

\begin{tabular}{lll}
\hline No & Item & $(\mathrm{r})$ \\
\hline 9 & I take care of my youngest child more than other because he is the last & $0.753^{* *}$
\end{tabular}

11 I compare my youngest child with his older brother or sister

$0.393^{*}$

22 I say to my son even if he the youngest among children that he is a man and $0.522^{* *}$ the man should not cry.

23 I tell my daughter to serve her brothers

$0.558^{* *}$

28 I give privilege for the boy because he will carry the family name or he is the $0.863^{* *}$ man of the home.

32 I take care of my daughter more than my son in terms of buying new cloths $0.592^{* *}$ and lay of her hair

The results in Table (7) showed that all values of the correlations were significant. 5 of them were at the level of 0.01 and only one at 0.05 level. Item no. 28 had the highest correlation.

Table 8. Correlation between the score of single items and the total score of Cruelty parenting style (dimension6)

\begin{tabular}{lll}
\hline No & Item & $(\mathrm{r})$ \\
\hline 10 & I slap my child on his face when I become angry & $0.620^{* *}$ \\
& & 0.264 \\
15 & I use terms such as you do not have a brain to think & \\
25 & I beat my child when he acts aggressively towards others to prevent doing it & $0.740^{* *}$ \\
& again & $0.708^{* *}$ \\
41 & I threaten my child when he tells lies & $0.413^{*}$ \\
46 & I threaten my child that I will beat him $\backslash$ her when cry & $0.681^{* *}$ \\
58 & I beat my child when he says bad words & \\
\hline
\end{tabular}

The results in Table (8) showed that all the correlations were significant at level 0.01 except one which was for item no. 46 at 0.05 level. Item no. 25 has highest correlation.

Table 9. Correlation between the score of single item and the total score of neglect parenting style (dimension 7)

\begin{tabular}{lll}
\hline & Item & $\mathrm{r}$ \\
\hline 7 & I leave my child alone with the maid & 0.216 \\
20 & I set with my child when he does his homework & 0.211 \\
21 & I ask my child about his friends & 0.280 \\
37 & I pay attention to my child' cry & 0.063 \\
47 & I engage in work to the extent that I forget to pick up my child from & 0.202 \\
& school & $0.965^{* *}$ \\
73 & I attend parents' meeting in my child's school & \\
\hline
\end{tabular}

The results in Table (9) showed only one significant correlation which was for item no. 73 at level 0.01 .
Final form of Parenting styles instrument 
International Journal of Childhood, Counselling, \& Special Education (CCSE), Volume1, Issue: 1 , September: 2020, pp.58-78

Based on the results of the permissive, discriminative, and reliability and the validity in the above tables, only 31 items out of 74 were selected to form the Parenting styles instrument. However, accepting and neglect parenting styles were removed because of the limited number of items in each style (1-2 items only). According to the pilot study, the form of Parenting styles instrument is composed of 28 items which represents 5 parenting styles only (authoritative, authoritarian, protective and punitive).

\section{Results}

\section{Validation of Parenting Styles Instrument}

\section{Construct validity}

The researcher used factor analysis as an evidence of construct validity to find the inter correlation between the items in the parenting style instrument.

Table 10. Factor analysis of parenting styles instrument; its validity and reliability among Bahraini mothers of preschool children (validity)

\begin{tabular}{|c|c|c|c|c|}
\hline \multirow[t]{2}{*}{ No } & \multirow[t]{2}{*}{ Items } & \multicolumn{3}{|c|}{ Validity } \\
\hline & & 1 & 2 & 3 \\
\hline 1 & I discuss with my child things concerned him before taking decision & & & 0.540 \\
\hline 2 & I consider my child's wishes in the family plans (weekend plan) & & & 0.635 \\
\hline 5 & I threat my child of punishment, but I change my mind after a while & 0.472 & & \\
\hline 6 & I stop punishment for my child before the preset time & 0.561 & & \\
\hline 8 & The punishment my child receives depends on my mood at that time & 0.539 & & \\
\hline 9 & I take care of my youngest child more than other because he is the last & 0.448 & & \\
\hline 10 & I slap my child on his face when I become angry & 0.588 & & \\
\hline 11 & I compare my youngest child with his older brother or sister & 0.524 & & \\
\hline 14 & I take my child for shopping to select his own clothes and toys & & & 0.536 \\
\hline 18 & I tell my child my point of view in the problems that he comes across & & & 0.477 \\
\hline 22 & $\begin{array}{l}\text { say to my son even if he the youngest among children that he is a man and the man should } \\
\text { not cry, but bears }\end{array}$ & & 0.340 & \\
\hline 23 & I tell my daughter to serve her brothers & 0.425 & & \\
\hline 25 & I beat my child when he acts aggressively towards others to prevent doing it again & 0.450 & 0.418 & \\
\hline 27 & I yell at my child when he bothers me or does what I disapprove & 0.570 & 0.303 & \\
\hline 29 & If my child attempted to talk I stop him vigorously & 0.544 & & \\
\hline 30 & I use harsh words which hurt when he misbehaves & 0.559 & & \\
\hline 32 & $\begin{array}{l}\text { I take care of my daughter more than my son in terms of buying new cloths and lay of her } \\
\text { hair }\end{array}$ & 0.365 & & \\
\hline 40 & I force him/her to eat certain food and cloths & 0.514 & 0.301 & \\
\hline 41 & I threaten my child when he tells lies & & 0.734 & \\
\hline 44 & I do not allow him $\backslash$ her to discuss my instructions & 0.454 & 0.360 & \\
\hline
\end{tabular}


International Journal of Childhood, Counselling, \& Special Education (CCSE), Volume1, Issue: 1 , September: 2020, pp.58-78

\begin{tabular}{lll}
\hline 46 & I threaten my child that I will beat him \her when cry & 0.759 \\
48 & I respect my child his opinion even if it is different than mine & 0.424 \\
57 & I do not allow him \her to participate in the school trips for fear it & 0.654 \\
58 & I beat my child when he says bad words & 0.685 \\
63 & I talk or express myself when my child misbehaves & -0.389 \\
\hline
\end{tabular}

Table (10) showed that 3 factors which were extracted using criterion

of minimum loading of 0.3 . In case an item is presence in two factors, its higher value will be considered. These factors were named as follows:

1. Factor 1 (The general factor): Authoritarian style (Loaded with 14 items)

2. Factor 2: Cruelty style (Loaded with 5 items)

3. Factor 3: Authoritative style (Loaded with 6 items)

According to the results the Authoritarian style is the most prevalence parenting style in Bahrain. Based on the results the validity of the instrument is moderate.

\section{Reliability}

Table 11. Cronbach alpha values for each factor and the whole instrument

\begin{tabular}{ll}
\hline Parenting style & Cronbach Alpha \\
\hline Authoritarian & 0.816 \\
Cruelty & 0.723 \\
Authoritative & 0.500 \\
The whole instrument & 0.755 \\
\hline
\end{tabular}

Table (11) showed that the reliability for the whole instrument and two parenting styles
(Authoritarian and Cruelty) were high but for the Authoritative style was low. 
International Journal of Childhood, Counselling, \& Special Education (CCSE), Volume1, Issue: 1 , September: 2020, pp.58-78

Table 12. The cutting score for Parenting Styles and the numbers of mothers below and above average for each style

\begin{tabular}{|c|c|c|c|c|c|c|c|c|}
\hline \multirow[t]{2}{*}{ Style } & \multirow{2}{*}{$\begin{array}{l}\text { No of } \\
\text { items }\end{array}$} & \multicolumn{7}{|c|}{ Levels of the Style and number of mothers (n) } \\
\hline & & $\begin{array}{l}\text { Criterion } \\
\text { score of } \\
\text { Low }\end{array}$ & $\mathrm{n}$ & $\%$ & $\begin{array}{l}\text { Criterion } \\
\text { score } \\
\text { Average }\end{array}$ & $\begin{array}{l}\text { Criterion } \\
\text { score of } \\
\text { High }\end{array}$ & $\mathrm{n}$ & $\%$ \\
\hline Authoritarian & 12 & $\begin{array}{l}\text { Less than } \\
24\end{array}$ & 22 & 8.7 & $24-48$ & $\begin{array}{l}\text { More than } \\
48\end{array}$ & 108 & 42.69 \\
\hline Cruelty & 5 & $\begin{array}{l}\text { Less than } \\
10\end{array}$ & 47 & 18.58 & $10-20$ & $\begin{array}{l}\text { More than } \\
20\end{array}$ & 33 & 13.04 \\
\hline Authoritative & 6 & $\begin{array}{l}\text { Less than } \\
15\end{array}$ & 35 & 13.83 & $12-24$ & $\begin{array}{l}\text { More than } \\
24\end{array}$ & 30 & 11.86 \\
\hline
\end{tabular}

The researcher created a norm for each subscale in the parenting style instrument. The average is $2-4$ in 5 levels scale. The results in Table (12) showed that most of the mothers in the sample used the Authoritarian Style with their children. The difference between this style and the other two styles was large.

Table 13. Descriptive statistics for the 3 prevalence behavior problems among preschool children in Bahrain ( $n=255)$

\begin{tabular}{llll}
\hline Behavioral problem & \% of the sample & M & SD \\
\hline Attention deficits & 12.55 & 12.15 & 3.97 \\
Hyper activity and impulsiveness & 7.45 & 24.48 & 8.11 \\
Aggression & 6.27 & 13.10 & 4.60 \\
\hline
\end{tabular}

The results in Table (13) showed among the children from the that the presence of hyperactivity preschool teacher perspective who and impulsiveness was the highest participated in this research.

Table 14. Correlation between the three prevalence parenting styles and the three prevalence behavioral problems among preschool children in Bahrain $(\mathrm{N}=255)$

\begin{tabular}{|c|c|c|c|}
\hline Item & Authoritarian & Cruelty & Authoritative \\
\hline Authoritarian & - & & \\
\hline Cruelty & $0.567^{* *}$ & - & \\
\hline Authoritative & $-0.662^{* *}$ & $-0.444^{* *}$ & - \\
\hline Attention deficit & $-0.128^{*}$ & -0.049 & 0.029 \\
\hline $\begin{array}{l}\text { Hyperactivity and } \\
\text { Impulsiveness }\end{array}$ & $-0.136^{*}$ & -0.110 & 0.072 \\
\hline Aggression & $-0.168^{* *}$ & $-0.144^{*}$ & 0.104 \\
\hline
\end{tabular}

The results in Table (14) showed significant correlations between the three prevalence behavioral problems (attention deficit, hyperactivity and impulsiveness, and aggression) among preschool 
International Journal of Childhood, Counselling, \& Special Education (CCSE), Volume1, Issue: 1 , September: 2020, pp.58-78

children and the Authoritarian parenting style used by their mothers. The results also showed that aggressive behavioral problem had a significant correlation with cruelty parenting style.

\section{Discussion}

The main results of this study showed that the three-prevalence parenting style which Bahraini mothers of young children used were authoritarian, cruelty and authoritative styles respectively. It was found that $42.69 \%$ of the mothers in the sample used authoritarian parenting style with their young children, $13.04 \%$ of the mother used cruelty style and $11.86 \%$ used authoritative style. These results were not expected by the researcher. Based on the history of education in Bahrain and personal observation, the researcher anticipated that authoritative and permissive styles are the dominant parenting styles in Bahrain. The findings present are in agreement with the notion that Bahrain is a collective society similar to other countries in the middle-east and some Asian countries (Palut (2009). People seem to share similar identity and the group is considered more important than the individual. They are expected to show Loyality, obedience and interdepencey to the authority. The individual in such society (Bahrain) is expected to scarify himself/herself for the benefit of the group. It is possible that parenting style is influenced by this paradigm of collectivism. Parents in such society or culture use inconsistent parenting which is more controlling of their children (Dwairy, 2008). Accordingly, inconsistency could enhance the authoritarian style more than other styles.

Palut (2009) suggested to view parenting style through understanding "parental beliefs, perceptions of children and roles attributed to them, folk beliefs and practices, religious practices, parental strategies, fertility rates and a set of socio demographic factors serve" (p246).

Children learn through social interaction with their relatives before they join school. It is possible that the model which is dominant in both the society and home has an influence on the type of education pupils receive at school because the school is a segment of the society. In the school, the pupils learn to be dependent on their teachers which might continue even at university level (Alhajeri, 2010).

The present results are consistent with the findings of Atrees (2010) in Algeria where authoritarian style is the prevalence compare to others. The results are also in agreement with the results of Knight et al (1994) with Hispanic parents. They found that both authoritarian style and cruelty or 
International Journal of Childhood, Counselling, \& Special Education (CCSE), Volume1, Issue: 1 , September: 2020, pp.58-78

punitive are dominant. These findings could support the idea of the association between the collective or inconsistency in parenting and the use of authoritarian parenting style. The results of this study contradict the findings of Abu Taleb (2012) in Jordan. She found that the authoritative parenting style is the prevalence among Jordanian mothers. Actually, Jordan and Bahraini have almost similar culture. One main explanation for the difference is that the mothers in Abu Taleb (2012) study had training in child rearing; whereas in the present study the Bahraini mothers had no training. The researcher also thinks it has nothing to do with the educational levels of the mothers. Most of the Bahraini mothers who participated in the study had a university degree. The results also contradict the findings of Baumrind (1991) in European and American societies. It was found that the authoritative parenting style was the prevalence parenting style and it is due to the difference in cultures and maybe the consistency in parenting.

The results showed that $12.55 \%$ of the Bahraini preschool children in the sample had attention deficit, $7.45 \%$ hyperactivity and impulsiveness and $6.27 \%$ aggression problems. A significant correlation was found between two parenting styles authoritarian and cruelty used by Bahraini mothers and the three prevalence behavioral problems attention deficit, hyperactivity and impulsiveness, and aggression among Bahraini preschool children. Specifically, the authoritarian style is positively correlated with the three behavioral problems; whereas the cruelty style is positively correlated with aggressionc only. These results are consistent with the findings of Algusoon (1993) in Saudi Arabia who indicated an association between aggressive behavior in Saudi preschool children and authoritarian parenting style. The two societies have almost the same culture and standard of living.

The results are also in agreement with Mehriz (2005) findings in Syria and Atrees (2010) in Algeria regarding the relationship between mothers' use of authoritarian, punishment or cruelty and negative behavioral problems. However in Atrees (2010) cruelty was associated with all the behavioral problems whereas in the present study cruelty style was associated with only aggressive behavior and the authoritarian style is connected with the three prevalence behavioral problems among Bahraini preschoolers.

\section{Recommendation}

1. A further study of parental styles is required using a larger sample.

2. Training in parenting practice is important for parents in order to 
International Journal of Childhood, Counselling, \& Special Education (CCSE), Volume1, Issue: 1 , September: 2020, pp.58-78

provide young children with emotional stability and appropriate learning.

\section{References}

Abu Taleb, T. F. (2012). Parenting styles and children's social skills as perceived by Jordanian mothers of preschool children. Early Child Development and Care, 1-15. Retrieved from

http://dx.doi.org/10.1080/03004430.2012.7 44988 on $1 / 6 / 2013$.

Al Hajeri, A. (2010). Screening reading, writing and numeracy learning problems in Bahraini young children aged 5-7 years. Unpublished doctoral dissertation, University of Strathclyde, Glasgow, Scotland.

Al Hajeri, A. (2014). Prevalence behavioral problems among preschool children in the Kingdom of Bahrain. Educational and Psychological Sciences Journal, 15(1), 13-92, https://doi.org/10.12785/jeps/150101

Algusoon, M. (1993). The relationship between parenting styles and aggressive behavioral among preschoolers in Riyad city. Arabian Gulf Message, 13(45). Retrieved from www.moalem.net on 1/6/ 2013.

Alizadeh, H. \& Andries, C. (2002). Interaction of parenting styles and attention deficit hyperactivity disorder in Iranian parents. Child $\mathcal{G}$ Family Behavior Therapy, 24(3), 37-52. https://doi.org/10.1300/j019v24n03_03

Atress, N. (2010). The relationship between negative parenting styles and behavioral problems among preschool children. Tawasal 26, 224251.

Baumrind, D. (1971). Current patterns of parental authority. Developmental Psychology, 4, 1-103. https://doi.org/10.1037/h0030372

Baumrind, D. (1991). The influence of parenting styles on adolescence competence and substance use. Journal of Early Adolescence, 11(1), 5695.

https://doi.org/10.1177/0272431691111004 Calzada, E. \&. Eyberg, S. (2010). Self-reported parenting practices in Dominican and Puerto Rican mothers of young children. Journal of Clinical Child E⿱ Adolescent Psychology, 31:3, 354-363. Retrieved from http://www.tandfonline.com/doi/pdf on 20/6/2013.

Deater-Deckerd, K., Dodge, K., Bates, J. E., \& Pettit, G. S. (1986). Physical discipline among AfricanAmerican and European American mothers: Links to children's externalizing behaviors. Developmental Psychology, 32(6), 1065-1072. 
International Journal of Childhood, Counselling, \& Special Education (CCSE), Volume1, Issue: 1 , September: 2020, pp.58-78

Dekovic, M., \& Janssens, J. (1992).

Parents' child-rearing style and child's sociometric status. Developmental Psychology, 28, 925932. https://doi.org/10.1037/00121649.28.5.925

Denham, S., Workman, E., Cole, P., Weissbrod, C., Kendziora, K., \& Zahn-Waxler, C. (2000). Prediction of externalizing behavior problems from early to middle childhood: The role of parental socialization and emotion expression. Development $\mathfrak{E}$ Psychopathology, 12, 23-45.

https://doi.org/10.1017/s095457940000102 4

Dwairy, M., Achoui, M., Abouserie, R., Farah, A., Sakhleh, A., Fayad, M., \& Khan, H. (2006). Parenting styles in Arab societies: A first crossregional research study. Journal of Cross-Cultural Psychology, 37: 230247. Retrieved from http://icc.sagepub.com/content/37/3/230 on $14 / 6 / 2013$.

Dwairy, M. (2008). Parental inconsistency versus parental authoritarianism: Associations with symptoms of psychological disorders.

Youth Adolescence, 37:616-626. https://doi.org/10.1007/s10964-007-9169-3

Garcia, F., \& Enrique Gracia, E. (2009). Is always authoritative the optimum parenting style? Evidence from Spanish families. Adolescence, 44(173), 101-131.
Glascoe, F. \& Leew, S. (2010). Parenting behaviors, perceptions, and psychosocial risk: Impacts on young children's development. Pediatrics, 125(2)125-313 Retrieved from

http://pediatrics.aappublications.org/conten t/125/2/313.full.html on 5/1/2014.

Hurd, E. P., Moore, C., \& Rogers, R. (1995). Quiet success: Parenting strengths among African Americans. Families in Society, 76, 434-443. https://doi.org/10.1177/1044389495076007 05

Knight, G. P., Virdin, L. M., \& Roosa, M. (1994). Socialization and family correlates of mental health outcomes among Hispanic and Anglo-American children: Consideration of cross-ethnic scalar equivalence. Child Development, 65, 212-224.

https://doi.org/10.2307/1131376

Kochanska, G. (1991). Socialization and temperament in the development of guilt and conscience. Child Development, 62, 1379-1392. https://doi.org/10.2307/1130813

Lamborn, S. D., Mants, N. S., Steinberg, L., \& Dornbusch, S. M. (1991). Patterns of competence and adjustment among adolescents from authoritative, authoritarian, indulgent, and neglectful families. Child Development, 62, 1049-1065. https://doi.org/10.2307/1131151 
International Journal of Childhood, Counselling, \& Special Education (CCSE), Volume1, Issue: 1 , September: 2020, pp.58-78

Latouf, N. (2008). Parenting styles affecting the behavior of five years olds. Dissertation of Master in Diaconiology - University of South Africa. $\quad$ Retrieved from http://uir.unisa.ac.za/bitstream/handle/1050 0/732/dissertation.pdf

on 14/6/2013.

Lin, C. C., \& Fu, V. R. (1990). A comparison of child-rearing practices among Chinese, immigrant Chinese, and Caucasian- American parents. Child Development, 61, 429-433. https://doi.org/10.2307/1131104

Mehriz, N. (2005). The relationship between parenting styles and social and personal interaction in preschool. Damascus University Journal,12 (1), 285-324. Retrieved from

http://www.damascusuniversity.edu.sy/m ag/edu/2010-02-14-13-53-20/45-21-2005 on $1 / 6 / 2013$.

O'Reilly, J. P., Tokuno, K. A., \& Ebata, A. T. (1986). Cultural differences between Americans of Japanese and European ancestry in parental valuing of social competence. Journal of Comparative Family Studies, 17, 87-97.

https://doi.org/10.3138/jcfs.17.1.87

Palut. B. (2009). A review on parenting in the Mediterranean Countries. C.Ü. Sosyal Bilimler Dergisi, 35(2) 242-247. Retrieved from

http://dergipark.ulakbim.gov.tr/cumusos bil/article/view/1008000419 on 30th
Jan. 2014.

Pearson, E., \& Rao, N. (2003). Socialization goals, parenting practices and peer competence in Chinese and English preschoolers. Early Child Development and Care, 173(1), 131-146.

https://doi.org/10.1080/0300443022000022 486

Querido, J. G., Warner, T. D., \& Eyberg, S. M. (2002): Parenting styles and child behavior in African American families of preschool children. Journal of Clinical Child $\mathbb{E}$ Adolescent Psychology, 31(2), 272-277. http://dx.doi.org/10.1207/S15374424JCCP3 102_12

Robinson, C., Mandleco, B., Frost Olsen, S., \& Hart, C. (1995). Authoritative, authoritarian, and permissive parenting practices: Development of a new measure. Psychological Reports, 77, 819-830. https://doi.org/10.2466/pr0.1995.77.3.819

Webster-Stratton, C. (1988). Mothers' and fathers' perceptions of child deviance: Roles of parent and child band parent adjustment. Journal of Consulting and Clinical Psychology, 56 (6) 909-915. https://doi.org/10.1037/0022-006x.56.6.909 